\title{
Evaluasi Layanan Broadband Campus Dengan Menggunakan Framework COBIT 4.1
}

\author{
Fajar Tri Prabowo ${ }^{1}$, NMAE Dewi Wirastuti ${ }^{2}$, I Nyoman Satya Kumara ${ }^{3}$
}

\begin{abstract}
Broadband campus is a high speed internet service with high transfer rate that implemented within the campus area. The sole purpose of this service is to optimize the internet network in certain area that is still lack of a high speed internet connection. This paper will ellaborate more on the evaluation of certain ongoing broadband campus service at Mahasaraswati University in Denpasar by using COBIT 4.1 Framework. This evaluation is intended to enhance the user effectiveness through existing services. This evaluation was conducted through certain mini-survey by using the broadband campus IT service by examining the university students satisfaction through series of interviews and questionnaires. The conclusion that was inferred through the surveys is that the broadband services within the university gain a subsequently low existing maturity level with 1.9 mark in the COBIT Framework scale. One of the major reason of why the service acquire low satisfaction level within the university is due the students in Mahasaraswati University did not manage to optimize the broadband campus service in the first place
\end{abstract}

Intisari - Broadband campus merupakan suatu layanan internet dengan kecepatan transfer yang tinggi yang diimplementasikan di area kampus, tujuan dari layanan ini adalah untuk mengoptimalkan jaringan internet di area kampus yang masih belum optimal. Paper ini membahas evaluasi layanan broadband campus yang telah berjalan yaitu broadband campus Universitas Mahasaraswati Denpasar dengan menggunakan framework COBIT 4.1, evaluasi ini bertujuan untuk meningkatkan efektivitas pengguna dari layanan existing yang telah berjalan. Proses evaluasi dilakukan dengan cara menggali informasi langsung pada layanan TIK broadband campus, dimana sumber data pada penelitian ini diperoleh langsung dari hasil informasi wawancara dan pengisian kuisioner oleh responden yaitu mahasiswa Universitas Mahasaraswati Denpasar. Kesimpulan yang didapatkan dalam paper ini adalah evaluasi layanan broadband campus Universitas Mahasaraswati Denpasar dengan menggunakan framework COBIT 4.1 mendapatkan hasil nilai maturity level existing yang masih sangat rendah yaitu $1,9$. Berdasarkan hasil wawancara langsung nilai yang rendah itu disebabkan karena masih belum optimalnya awareness civitas akademika terhadap layanan ini.

Kata Kunci - Broadband, COBIT 4.1, Framework, Awareness

\footnotetext{
${ }^{1}$ Mahasiswa, Magister Teknik Elektro Universitas Udayana, Gedung Pascasarjana Universitas Udayana Jl. PB Sudirman Denpasar-Bali $80232 \quad$ (tlp/fax: $0361-239599 ; \quad$ e-mail: fajar_mcr@yahoo.com)

2, Dosen Magister Teknik Elektro Universitas Udayana, Gedung Pascasarjana Universitas Udayana Jl. PB Sudirman Denpasar-Bali 80232 (tlp/fax: 0361-239599; e-mail: dewi.wirastuti@unud.ac.id)

${ }^{3}$ Dosen Magister Teknik Elektro Universitas Udayana, Gedung Pascasarjana Universitas Udayana Jl. PB Sudirman Denpasar-Bali 80232 (tlp/fax: 0361-239599; e-mail: satya.kumara@unud.ac.id)
}

Fajar Tri Prabowo : Evaluasi Layanan Broadband Campus...

\section{PENDAHULUAN}

Infrastruktur telekomunikasi di era globalisasi telah mengalami peningkatan yang sangat signifikan, era teknologi broadband yang dapat didefinisikan sebagai jaringan atau service internet yang memiliki kecepatan transfer yang tinggi telah menjadi suatu kebutuhan semua pelosok negeri. Sehingga munculah kota yang dikenal dengan istilah broadband city, yaitu kota yang akses jaringan dan service internetnya telah memiliki kecepatan yang baik [1].

Teknologi broadband ini juga dikembangkan dalam bidang pendidikan yaitu dengan diimplementasikannya broadband di area lembaga pendidikan seperti sekolah dan kampus. Layanan broadband ini dikenal dengan istilah layanan broadband school dan broadband campus. Salah satu layanan broadband campus yang telah berjalan dalam lembaga pendidikan adalah implementasi layanan broadband campus flash lounge Telkomsel di Universitas Mahasaraswati Denpasar. Layanan broadband campus ini merupakan salah satu media akses pengembangan broadband bagi kampus yang belum memiliki akses broadband yang baik dalam infrastruktur jaringannya[2].

Tetapi apabila dilihat dari efektivitas pengguna broadband campus ini belum terlalu optimal pemakaiannya, dimana layanan broadband campus yang telah dijalankan di Universitas Mahasaraswati Denpasar penggunaanya masih dibawah target dari total mahasiswa yang ada. Adapun target yang diinginkan penyedia layanan adalah semua civitas akademika memanfaatkan layanan tersebut, sehingga dengan report belum optimalnya efektifitas layanan ini memberikan informasi bahwa perlu adanya evaluasi terhadap layanan TIK broadband campus ini [3].

Terdapat beragam kerangka kerja (framework) yang dapat digunakan untuk melakukan evaluasi terhadap layanan TIK, dalam paper ini kerangka kerja yang digunakan adalah framework COBIT (Control Objectives for Information and Related Technology). COBIT adalah tata kelola yang paling banyak digunakan karena mampu menyediakan dukungan yang kuat untuk audit layanan TIK, meminimalisasi biaya resiko audit, dan mampu meningkatkan kualitas dan opini audit[4].

Dari beberapa penelitian yang telah berjalan, framework COBIT 4.1 masih menjadi prioritas pilihan dalam melakukan audit. Sebagai contoh dalam penelitian [5] Penelitian ini menitikberatkan pada evaluasi sistem informasi mengunakan kerangka audit COBIT 4.1. Fokus penelitian pada domain PO dimana dalam skala maturity level adalah skala 3 . Hal ini menunjukkan bahwa belum adanya SOP yang jelas untuk melaksanakan kegiatan di lingkungan koperasi, dimana prosedur-prosedur sistem informasi yang ada di koperasi Swadharma belum di implementasikan secara optimal.[6]

p-ISSN:1693 - 2951; e-ISSN: 2503-2372 
Dimana dalam penelitian ini membahas tentang analisis dan monitoring implementasi teknologi informasi perguruan tinggi menggunakan COBIT 4.1. Dimana hasil yang didapatkan adalah pemanfaatan tata kelola COBIT 4.1 dapat mengarahkan implementasi teknologi informasi dalam mendukung tercapainya visi Universitas Gadjah Mada untuk menjadi universitas riset kelas dunia. Pada penelitian [7] digunakan framework COBIT 4.1 untuk mengidentifikasi sejauh mana kepuasan pengguna layanan IT, serta pengukuran tingkat kematangan proses. Hasil dari tahapan tersebut menunjukan adanya permasalahan dan gap antara tingkat kematangan proses saat ini dengan yang diharapkan.

Berdasarkan beberapa penelitian yang telah ada sebelumnya, jika dilihat dari aspek metodeloginya COBIT 4.1 mampu memberikan standar penilaian evaluasi untuk konsep pengembangan dan perbaikan kinerja. Oleh karena itu pada paper ini, framework COBIT 4.1 menjadi acuan dalam upaya pelaksanaan evaluasi layanan broadband campus di Universitas Mahasaraswati Denpasar.

\section{DASAR TEORI}

\section{A. Broadband Campus Flash Lounge Telkomsel}

Broadband campus flash lounge Telkomsel merupakan suatu implementasi broadband yang diimplementasikan khusus untuk ruang lingkup pendidikan yaitu kampus dan sekolah-sekolah [2]. Fasilitas yang tersedia di flash lounge sendiri terbilang eksklusif, Telkomsel menyediakan perangkat gadget laptop dan sejenisnya hingga tablet yang digunakan secara gratis yang bertujuan untuk mengedukasi mahasiswa agar semakin melek teknologi di era digital. Flash lounge diimplementasikan di area kampus yang dirancang sebagai tempat yang nyaman bagi mahasiswa untuk mengakses beragam informasi dan saling berdiskusi dengan santai, sambil menikmati layanan koneksi internet yang cepat dengan $\mathrm{WiFi}$ flash zone yang berkecepatan hingga $100 \mathrm{Mbps}$ secara gratis. Flash lounge di desain dengan nuansa yang cozy agar mahasiswa serta yang berada di lingkungan Universitas Mahasaraswati Denpasar semakin leluasa dan nyaman dalam mengakses internet memanfaatkan layanan WiFi flash zone guna menunjang kegiatan belajar maupun kebutuhan informasi lainnya. Di area seluas 50 meter persegi tersebut, pengguna flash lounge bisa memperoleh informasi mengenai berbagai produk dan layanan Telkomsel. Telkomsel juga menyediakan beberapa fasilitas lainnya yang dapat digunakan untuk meningkatkan tingkat penggunaan mahasiswa dalam penggunaan layanan ini, antara lain :

1) Web2SMS : Merupakan fasilitas sistem informasi sebagai sarana penyampaian informasi seputar kegiatan sekolah dan kampus kepada pelajar dan mahasiswa melalui SMS. Implementasi ini dapat digunakan sebagai sumber informasi terkait kegiatan kampus seperti hasil ujian, hasil IPK sementara dan informasi jadwal UAS maupun UTS bagi mahasiswa yang aktif menggunakan mobile selular.

2) Implementasi seemless mobile : Merupakan layanan WiFi yang dikhususkan untuk pengguna mobile selular yaitu handphone dan tablet, implementasi ini bisa digunakan secara gratis bagi pengguna yang berada dalam ruang lingkup area broadband campus flash lounge Telkomsel.
3) Implementasi paket campus : Dikenal dengan paket hebat kampus merupakan paket gratis nelpon dan SMS yang diberikan Telkomsel bagi subscriber yang aktif sebagai komunitas kampus/sekolah yang dapat digunakan untuk berkomunikasi sesama komunitas tersebut.

\section{B. COBIT 4.1}

COBIT (Control Objectives for Information and Related Technology) adalah salah suatu tata kelola (Framework) yang dikembangkan oleh Information Systems Audit and Control Association (ISACA) dan IT Governance Institute (ITGI) pada tahun 1992, untuk organisasi dan manajemen teknologi informasi. COBIT merupakan seperangkat pendukung yang menjembatani celah antara persyaratan pengaturan (kontrol), isu-isu teknis, dan resiko bisnis. Konsep dasar pada kerangka kerja COBIT adalah menentukan kendali dalam bidang TI yang didasarkan pada informasi yang dibutuhkan dalam upaya untuk mendukung tujuan bisnis dari suatu organisasi/instansi [8]. COBIT 4.1 dirancang terdiri dari 34 high level control objectives yang menggambarkan proses TI yang terdiri dari 4 domain yaitu:

- Plan and organise

- Acquire and implement

- Deliver and support

- Monitor and evaluate

Untuk lebih jelasnya pembagian COBIT 4.1 dapat dilihat pada gambar 1 [4].

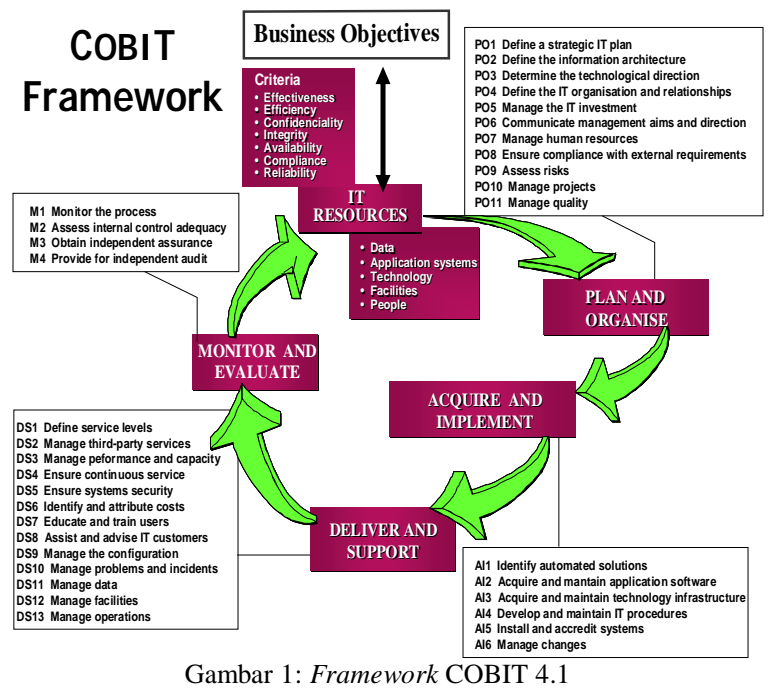

Salah satu alat pengukuran dari kinerja suatu sistem teknologi informasi pada COBIT 4.1 adalah dengan nilai kematangan (maturity level). Nilai kematangan untuk pengelolaan dan pengendalian pada proses teknologi informasi didasarkan pada metode evaluasi organisasi sehingga dapat dinilai dari level 0 (tidak ada) hingga level 5 (optimized). Nilai kematangan dimaksutkan untuk mengetahui keberadaan persoalan yang ada dan bagaimana menentukan prioritas peningkatan. Nilai kematangan dirancang sebagai profil proses teknologi informasi, sehingga organisasi akan dapat mengenali sebagai deskripsi kemungkinan keadaan 
sekarang dan mendatang. Pada gambar 2 dijelaskan level penilaian maturity level dari level 0 - level 5 [4].

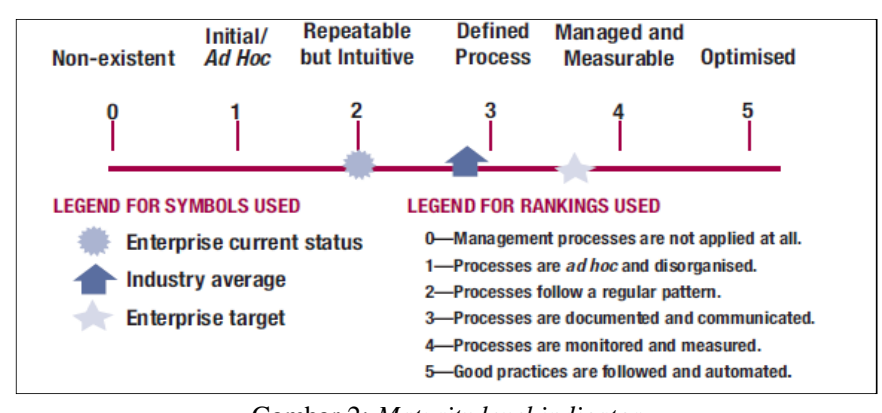

Gambar 2: Maturity level indicator

Keterkaitan antara masing-masing domain pada COBIT 4.1 dapat digambarkan pada gambar 3. Pada domain plan and organise (PO) memberikan panduan atau arahan untuk memberikan solusi (AI) dan layanan (DS), domain acquire and implement (AI) menyediakan solusi dan merubahnya menjadi sebuah layanan. Sedangkan domain deliver and support (DS) menerima solusi dan menjadikan solusi tersebut berguna bagi pengguna, serta domain monitor and evaluate (ME) memonitor seluruh proses dan memastikan arahan pimpinan agar diikuti [10].

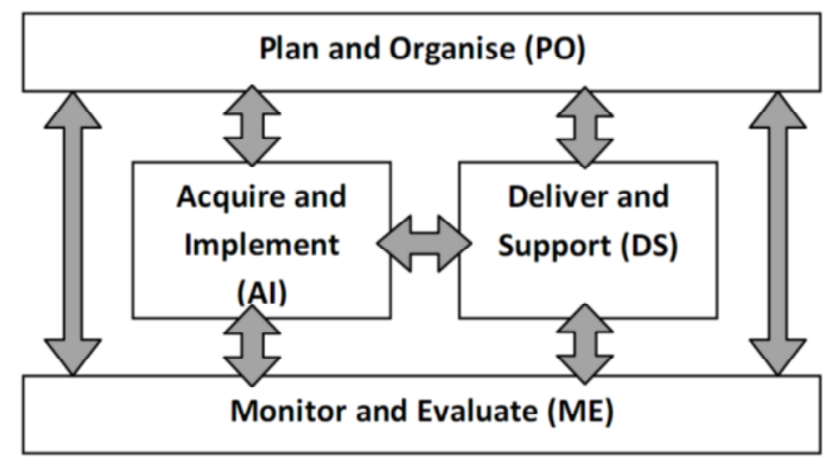

Gambar 3 : Hubungan tiap domain COBIT 4.1

\section{Perhitungan Sampel Minimum Responden}

Berdasarkan data dari Universitas Mahasaraswati Denpasar jumlah mahasiswa dari angkatan 2012 - 2014 adalah sebanyak 6150 mahasiswa. Total responden mahasiswa yang digunakan dimulai dari tahun 2012 disebabkan layanan broadband campus ini baru diimplementasikan tahun 2014 dan berdasarkan data statistik mahasiswa yang masih aktif ke kampus paling efektif angkatan diatas tahun 2012. Sebagai penentu jumlah sampel maka penulis menggunakan metode Slovin [11], yang menggunakan batas toleransi kesalahan sebesar $10 \%$.

Mengacu pada (1) jumlah perhitungan sampel minimum dapat dirumuskan sebagai berikut :

$$
n=\frac{N}{1+N e^{2}}
$$

Dengan $n$ adalah ukuran sampel yaitu jumlah minimal responden yang akan digunakan (satuannya adalah jumlah orang), $\mathrm{N}$ adalah ukuran populasi yaitu jumlah keseluruhan populasi (satuannya adalah jumlah orang) dan e adalah tingkat Fajar Tri Prabowo : Evaluasi Layanan Broadband Campus... kesalahan yang ditoleransi (satuannya adalah persentase). Sehingga untuk perhitungan sampel minimum responden pada paper ini mengacu pada (1) dapat dihitung sampel minimum responden sebagai berikut :

$$
n=\frac{6150}{1+6150(0,1)^{2}}=98,99=99
$$

Ukuran sampel minimum responden yang harus dipenuhi pada evaluasi broadband campus Universitas Mahasaraswati Denpasar adalah dengan minimum 99 responden.

\section{METODELOGI}

Paper evaluasi layanan broadband campus ini bersifat kualitatif dan eksploratif artinya penelitian dilakukan dengan cara menggali informasi langsung untuk layanan TIK broadband campus flash lounge Telkomsel yang berlangsung di Universitas Mahasaraswati Denpasar. Sumber data pada paper ini diperoleh dari informasi hasil wawancara dan pengisian kuisioner oleh responden/ pihak-pihak yang memiliki keterkaitan terhadap evaluasi layanan broadband campus Flash lounge Telkomsel, adapun responden pada evaluasi broadband campus ini adalah pengguna layanan broadband campus yaitu mahasiswa Universitas Mahasaraswati Denpasar.

Tahap awal adalah observasi langsung layanan broadband campus yang telah berjalan di Universitas Mahasaraswati Denpasar, yang bertujuan untuk megetahui permasalahan existing sehingga bisa dilakukan pemilihan metode evaluasi. Tahap selanjutnya adalah proses seleksi domain COBIT 4.1, dilakukan seleksi domain framework COBIT 4.1 didasari dari tujuan bisnis perusahaan dan tujuan IT kampus [12]. Setelah proses seleksi domain dilakukan proses selanjutnya adalah pembuatan kuisioner sesuai dengan domain yang telah ditentukan, pembuatan kuisioner ini bertujuan untuk mengetahui nilai maturity level dari objek yang ingin di evaluasi. Setelah pembuatan kuisioner selesai tahap selanjutnya adalah pengumpulan data dengan penyebaran kuisioner ke responden yang telah ditentukan.

Tahap berikutnya adalah data processing merupakan proses pengelolahan hasil kuisioner dan dilakukan perhitungan sehingga didapatkan nilai maturity level terhadap objek yang telah dilakukan evaluasi dengan bantuan aplikasi Microsoft excel. Analisa data dilakukan dengan cara menghitung nilai maturity level pada kondisi eksisting berdasarkan data hasil pengisian kuisioner, selanjutnya dibandingkan dengan level maturity yang ingin dituju oleh Perusahaan. Tahap akhir adalah penyusunan rekomendasi terkait hasil evaluasi dan level maturity yang telah didapatkan pada layanan broadband campus flash lounge Telkomsel di Universitas Mahasaraswati Denpasar.

\section{HASIL DAN PEMBAHASAN}

Analisis nilai maturity level dilakukan untuk mengetahui kondisi saat ini, serta proyeksi kondisi kedepan yang diharapkan. Pengumpulan datanya dilakukan dengan cara pengisian kuisioner langsung terhadap responden yaitu mahasiswa Universitas Mahasaraswati Denpasar.

p-ISSN:1693 - 2951; e-ISSN: 2503-2372 


\section{A. Perhitungan Maturity Level Layanan Broadband Campus}

Perhitungan nilai maturity level dengan menggunakan domain yang telah diseleksi sebelumnya yaitu domain plan and organize (PO), domain delivery and support (DS) dan domain monitor and evaluate (ME). Didapatkan tingkat maturity level yang diperoleh dengan menghitung jumlah ratarata tingkat maturitas aktivitas pada setiap proses.

1) Domain $D S$ : Fokus pemilihan domain DS adalah sub domain DS1 - DS5, pemilihan ini disesuaikan dengan permasalahan awareness pada layanan broadband campus. Hasil yang didapatkan pada perhitungan maturitas aktivitas pada domain DS seperti pada tabel 1 didapatkan rata-rata maturity level existing sebesar 1.4, dari maturity level tersebut dapat disimpulkan bahwa pada domain DS layanan broadband campus flash lounge Telkomsel masih sangat rendah yaitu masih di level 1. Pada level 1 masalah sudah diketahui perusahaan tetapi belum adanya prosedur standar yang digunakan untuk menyelesaikan masalah tersebut. Penggunaan sub domain DS1 adalah untuk menentukan dan mengelola tingkat layanan existing agar pengguna mengetahui sejauh mana fungsi dari layanan dan coverage area broadband campus ini [12], maturitas aktivitas dengan angka 1.36 yang menginformasikan masih rendahnya awareness pengguna terhadap layanan broadband campus. Dilanjutkan dengan penggunaan sub domain DS3 untuk mengetahui sejauh mana pengelolaan performa dan kapasitas TIK oleh pengguna, didapatkan maturitas aktivitas sebesar 1.88 yang juga masih rendah dalam maturitas umumnya. Sedangkan sub domain DS4 bertujuan untuk melihat proyeksi kedepan kelanjutan layanan existing dan sejauh mana prioritas layanan ini bagi pengguna, maturitas aktivitas berada pada nilai 1.43 ini dikarenakan belum mengertinya pengguna terhadap layanan broadband campus yang telah berjalan. dan yang terakhir adalah sub domain DS5 yaitu terkait dengan keamanan sistem dan layanan bagi pengguna. Untuk lebih jelasnya hasil maturity level domain DS dapat dilihat pada tabel 1.

TABEL 1

TABEL MATURITY AKTIVITAS DOMAIN DS

\begin{tabular}{|c|c|c|c|}
\hline Proses & Aktivitas & $\begin{array}{c}\text { Maturitas } \\
\text { Aktivitas }\end{array}$ & $\begin{array}{c}\text { Maturity } \\
\text { Level }\end{array}$ \\
\hline DS1 & 1 & 1.36 & \multirow{2}{*}{1.4} \\
\hline DS3 & 2 & 1.88 & \\
\hline DS4 & 3 & 1.43 & \\
\hline DS5 & 4 & 1.02 & \\
\hline
\end{tabular}

2) Domain $M E$ : Analisis domain selanjutnya adalah melakukan perhitungan maturitas aktivitas pada domain ME. Hasil yang didapatkan dapat dilihat pada tabel 2 yaitu rata-rata maturity level existing sebesar 2.3, dengan hasil ini diinformasikan bahwa maturity level ME masih rendah. Pada level 2 masalah sudah diketahui perusahaan dan prosedur standar sudah diterapkan juga, tetapi belum adanya pelatihan terhadap prosedur tersebut sehingga masih sering terjadi kesalahan. Pada pemilihan sub domain ME3 fokus pemilihan sub domain tersebut untuk mendapatkan input bahwa layanan ini berguna untuk pengguna serta dibutuhkan untuk pemakaiannya baik sekarang maupun proyeksi kedepannya. Existing nilai maturitas aktivitas pada nilai 2.11 dimana nilai ini masih cukup rendah dikarenakan belum optimalnya awareness pengguna. Sedangkan pada sub domain ME4 fokus pemilihan domain ini adalah untuk menetapkan TIK Governance layanan broadband campus agar sesuai dengan pihak internal dan penyedia layanan. Maturitas aktivitas masih cukup rendah yaitu pada nilai 2.64 sehingga perlu analisis pihak penyedia layanan agar bisa meningkatkan maturitas aktivitas sub domain terkait. Untuk lebih jelasnya hasil maturity level domain ME dapat dilihat pada tabel 2.

TABEL 2

TABEL MATURITY AKTIVITAS DOMAIN ME

\begin{tabular}{|c|c|c|c|}
\hline Proses & Aktivitas & $\begin{array}{c}\text { Maturitas } \\
\text { Aktivitas }\end{array}$ & $\begin{array}{c}\text { Maturity } \\
\text { Level }\end{array}$ \\
\hline ME3 & 5 & 2.11 & 2.3 \\
\hline ME4 & 6 & 2.64 & 2.3 \\
\hline
\end{tabular}

3) Domain PO : Analisis domain yang terakhir adalah melakukan perhitungan maturitas aktivitas pada domain PO, dapat dilihat pada tabel 3 didapatkan rata-rata maturity level existing sebesar 2.2, dari maturity level tersebut dapat disimpulkan bahwa pada domain PO layanan broadband campus flash lounge Telkomsel masih cukup rendah yaitu di level 2. Pada level 2 masalah sudah diketahui perusahaan dan prosedur standar sudah diterapkan tetapi belum adanya pelatihan terhadap prosedur tersebut dan tanggung jawab dibebankan pada masing-masing individu untuk menyelesaikan masalah sehingga terjadinya kesalahan masih sangat sering. Pemilihan sub domain PO3 bertujuan untuk pengembangan perencanaan infrastruktur kedepannya serta penentuan arah teknologi, pada analisis nilai maturitas aktivitas didapatkan nilai 1.78 masih cukup rendah karena masih banyak pengguna yang belum aware terkait layanan ini. sedangkan fokus sub domain PO4 adalah penentuan proses TIK, organisasi, serta sumber daya manusia untuk kedepannya. Untuk nilai maturitas aktivitas pada nilai 2.02 cukup baik karena sudah terbentuknya organisasi serta SDM untuk layanan broadband campus ini. Sub domain PO terakhir adalah sub domain PO6 yang fokus pada arah tujuan layanan broadband campus searah dengan tujuan manajemen serta tujuan yang diinginkan pihak kampus, untuk nilai maturitas sudah cukup baik yaitu 2.85 karena sudah sesuai dengan renstra dan tujuan penyedia layanan broadband campus. Untuk lebih jelasnya hasil maturity level domain PO dapat dilihat pada tabel 3 .

TABEL 3

TABEL MATURITY AKTIVITAS DOMAIN PO

\begin{tabular}{|c|c|c|c|}
\hline Proses & Aktivitas & $\begin{array}{c}\text { Maturitas } \\
\text { Aktivitas }\end{array}$ & $\begin{array}{c}\text { Maturity } \\
\text { Level }\end{array}$ \\
\hline PO3 & 7 & 1.78 & \multirow{2}{*}{2.2} \\
\hline PO4 & 8 & 2.02 & \\
\hline PO6 & 9 & 2.85 & \\
\hline
\end{tabular}

B. Perbandingan Maturity Level Layanan Broadband Campus Existing dengan Tujuan Perusahaan. 
Dari hasil maturitas aktifitas semua domain yang digunakan maka didapatkan nilai maturity level dari evaluasi layanan broadband campus flash lounge Telkomsel. Pada tabel 4 dapat dilihat perbandingan nilai maturity level existing dibandingkan dengan maturity level tujuan perusahaan.

TABEL 4

TABEL PERBANDINGAN MATURITY LEVEL

\begin{tabular}{|c|c|c|c|}
\hline Domain & $\begin{array}{c}\text { Maturity } \\
\text { Aktivitas }\end{array}$ & $\begin{array}{c}\text { Maturity } \\
\text { Existing }\end{array}$ & $\begin{array}{c}\text { Maturity } \\
\text { Tujuan }\end{array}$ \\
\hline DS & 1.4 & \multirow{2}{*}{1.9} & \multirow{2}{*}{4} \\
\cline { 1 - 2 } ME & 2.3 & & \\
\hline PO & 9 & & \\
\hline
\end{tabular}

Pada tabel 4 dapat dilihat gap yang cukup jauh dari nilai maturity level existing dengan target maturity level tujuan perusahaan yaitu dengan nilai 4. Pemilihan maturity level 4 ini bertujuan agar layanan TIK broadband campus ini sudah mengikuti prosedur yang tersedia serta tersedianya pengawasan langsung oleh management. Untuk peningkatan level tersebut diperlukan peningkatan step by step dari level existing, yaitu dengan meningkatkan level existing ke level 2, lanjut ke level 3 dan level tujuan yaitu level 4 semua ini dapat dilakukan dengan rekomendasi yang dapat diimplementasikan pada layanan broadband campus.

\section{Rekomendasi Peningkatan Maturity Level Layanan Broadband Campus}

1) Rekomendasi Peningkatan Maturity Level 2 : Step pertama untuk meningkatkan nilai maturity level dari nilai 1 menjadi 2 adalah dengan menjalankan rekomendasi sebagai berikut :

- Mengidentifikasi fasilitas yang dibutuhkan mahasiswa dalam menggunakan layanan broadband campus[9].

- Melakukan perencanaan layanan secara kontinu dan trial layanan secara jelas didefinisikan dan ditetapkan untuk memastikan pelayanan yang berkesinambungan.

- Mendefinisikan prosedur keamanan informasi yang selaras dengan kebijakan keamanan informasi dan diimplementasikan pada layanan broadband campus ini.

- Melakukan survey terhadap user terkait awareness user tentang layanan broadband campus dan memperbaiki kekurangan layanan existing broadband campus.

2) Rekomendasi Peningkatan Maturity Level 3: Step selanjutnya untuk meningkatkan nilai maturity level dari nilai 2 menjadi 3 adalah dengan menjalankan rekomendasi sebagai berikut :

- Review dan pengukuran sejauh mana performansi kinerja layanan broadband campus dari aspek kecepatan internet yang terimplementasi pada kampus Universitas Mahasaraswati Denpasar.

- Menjadikan target pihak internal terkait efektivitas layanan sebagai kesuksesan

Fajar Tri Prabowo : Evaluasi Layanan Broadband Campus... program layanan broadband campus yang di diskusikan setiap waktu tertentu.

- Report management quality sudah terschedule secara daily, weekly dan monthly dan diterima pihak yang bertanggung jawab dalam management quality layanan broadband campus.

- Melakukan perencanaan strategi peningkatan brand awareness layanan broadband campus dengan salah satunya pengenalan secara massal melalui ospek mahasiswa baru.

3) Rekomendasi Peningkatan Maturity Level 4: Step terakhir untuk meningkatkan nilai maturity level dari nilai 3 menjadi 4 adalah dengan menjalankan rekomendasi sebagai berikut :

- Peningkatan awareness layanan broadband campus dimaksimalkan dengan media cetak (flyer dan poster di area kampus), media suara (radio kampus), media internet (sosial media dan web kampus) [9].

- Maintenance dan control pihak penyedia layanan terhadap semua ketersedian fasilitas yang mendukung user dalam menggunakan layanan broadband campus.

- Meningkatkan pengawasan secara teratur dari pihak internal terkait kuaitas jaringan yang dipakai dalam implementasi layanan broadband campus.

- Melakukan quality control terhadap performa internet dan layanan pendukung dengan menggunakan media pengukuran yang bisa dilakukan pihak internal untuk mengetahui QoS dari layanan TIK broadband campus.

\section{KeSIMPUlan}

Hasil evaluasi dari layanan broadband campus flash lounge Telkomsel Universitas Mahasaraswati Denpasar di dapatkan nilai maturity level existing yang masih sangat rendah yaitu dengan nilai 1.9, berdasarkan hasil wawancara langsung nilai yang rendah itu disebabkan karena masih belum optimalnya awareness mahasiswa terhadap layanan ini. Untuk mencapai maturity level yang ingin dituju penyedia layanan yaitu pada level 4, diperlukan peningkatan step by step melalui rekomendasi di setiap peningkatan levelnya. Pemilihan level 4 merupakan tujuan dari perusahaan agar efektivitas user meningkat serta sesuai dengan referensi maturity level COBIT 4.1 yang menginformasikan pada level ini telah dilaksanakan controlling oleh management.

\section{REFERENSI}

[1] Kementrian Komunikasi dan Informatika Republik Indonesia. (2012). Perkembangan Broadband antara Pertumbuhan Ekonomi dan Kesejahteraan Warga. Jakarta : Rakornas Kominfo.

p-ISSN:1693 - 2951; e-ISSN: 2503-2372 
[2] Telkomsel. (2014). Flash Lounge Telkomsel Hadir di Universitas Mahasaraswati. News release Telkomsel Bali-Nusra.

[3] Telkomsel. (2015). Data IT Telkomsel. Diakses 10 Januari 2015

[4] Meadows, R. (2007). COBIT 4.1 Framework, Control Objective, Management Guidelines, Maturity Models, IT Governance Institute. USA: Information Technology Governance Institute.

[5] Darwas, R. (2010). Evaluasi Peran Sistem Informasi Manajemen Koperasi Swadarma dengan Menggunakan Model Maturity Level pada Kerangka Kerja COBIT pada Domain Plan and Organise. Jakarta: Program Magister Sistem Informasi Akuntansi, Universitas Gunadarma.

[6] Prasetyo, E. (2011). Analisis dan Monitoring Implementasi Teknologi Informasi Perguruan Tinggi Menggunakan Control Objective for Information and Related Technology (COBIT). Bali : Konferensi Nasional Sistem dan Informatika.

[7] Noviandi, V., Aradea., \& Mubarok, Husni. (2012). Tata Kelola Teknologi Informasi Menggunakan Kerangka Kerja COBIT Semarang : Prosiding Seminar Nasional Ilmu Komputer 2012, ISBN: 978-979-756-842-9
[8] Maulidia, N., Rochimah, S., \& Affandi, A. (2013). Pengembangan Prosedur Untuk Optimalisasi Kualitas Sistem dan Layanan Jaringan TIK dengan COBIT 4.1 dan ITIL V3. Surabaya: Prosiding Seminar Nasional Manajemen Teknologi XVII.

[9] Komang Isabella Anasthasia, Made Sudarma, I Made Arsa Suyadnya, "Pengembangan Aplikasi Layanan Informasi Kampus Pada Jurusan Teknik Elektro Universitas Udayana Berbasis Mobile dan Web Service", Majalah Ilmiah Teknologi Elektro, Vol. 13, No.2, Juli-Desember 2014.

[10] Indri, S. R. (2012). Model Perhitungan Tingkat Kedewasaan TI (Maturity Level) Menggunakan Framework COBIT 4.1. Jakarta: Seminar Nasional Teknik Informatika (SANTIKA) , 73-77.

[11] Yuliarmi, Ni Nyoman dan Putu Riyasa. (2007). Analisis Faktor-Faktor yang Mempengaruhi Kepuasan Pelanggan Terhadap Pelayanan PDAM Denpasar. Denpasar : Jurnal Buletin Studi Ekonomi Vol. 12 no 1, Hal 9-28

[12] Linawati, Nyoman Gunantara, I K A Riki Gunawan, "Performansi WLAN Kantor Pusat Pemerintahan Kabupaten Badung" Majalah Ilmiah Teknologi Elektro, Vol. 14, No.2, Juli-Desember 2015. 